\title{
COVID 19: SIN DISTINCIÓN DE RAZA, SEXO O POSICIÓN SOCIOECONÓMICA; NADIE ESTÁ SEGURO
}

\author{
COVID 19: WITHOUT DISTINCTION OF RACE, SEX OR SOCIOECONOMIC POSITION; NO ONE IS SAFE
}

Tello-majluf D., a

\begin{abstract}
Sr. Editor
He leído con placer y gratitud el artículo "Protección del personal de salud en la pandemia COVID-19" escrito por el Prof. Doctor Jhony De La Cruz, publicado el 21 de marzo de 2020 en esta prestigiosa revista.
\end{abstract}

En respuesta a este artículo muy ilustrativo sobre la pandemia de COVID-19, me gustaría expresar mi tristeza y compartir mi experiencia de lo que estamos viviendo, de primera mano, aquí en el epicentro de los Estados Unidos, la ciudad de Nueva York; pero primero déjenme comenzar por darles una idea de la línea de tiempo que ha tenido lugar este nefasto episodio, para llevarnos a donde estamos hoy. Como todos sabemos, había un médico que alerto y comunicó en Wuhan, China, su nombre era Li Wenliang, era un oftalmólogo. El 31 de diciembre de 2019, China confirmó la existencia del nuevo virus inicialmente llamado 2019-nCoV, ahora conocido como SARS-CoV2, pero el Dr. Li Wenliang dijo que había observado que muchos de sus colegas se enfermaron y observaron 4 muertes con el virus en los 2 meses anteriores a eso.

Antes que China reconociera el virus, habían castigado al Dr. Wenliang por "difundir rumores". No fue sino hasta el 21 de enero de 2020 que, un funcionario chino confirmó que había transmisión de persona a persona y ese mismo día, Estados Unidos observó su primer caso en el estado de Washington, así como en Vietnam, Singapur y Corea del Sur.

El 30 de enero, la OMS (Organización Mundial de la Salud) declaró una emergencia sanitaria mundial y ese día el Presidente Trump bloqueó todos los viajes desde China. El 11 de febrero de 2020, la OMS nombró la nueva enfermedad causada por el SARS-CoV2, COVID-19. No fue hasta el 13 de marzo de 2020 que finalmente se declara un estado nacional de emergencia en los Estados Unidos. Finalmente, el domingo 22 de marzo de 2020, el Gobernador Cuomo instaló un confinamiento para que todos los neoyorquinos se queden en casa a menos que sea un empleado esencial. ¿Qué significa esto? los empleados esenciales incluyen personal de primeros auxilios, trabajadores de la salud, médicos, enfermeras, técnicos, etc., investigadores y servicios de laboratorio, servicios veterinarios, servicios públicos de generación de energía, cualquier tipo de viaje, supermercados, restaurantes, tiendas de conveniencia, farmacias, lavandería, etc. todo lo que requiera necesidades esenciales de las personas.

Lamentablemente, la respuesta de los Estados Unidos llegó demasiado tarde y ahora nos encontramos en una situación devastadora a la que nos enfrentamos todos los días. Los trabajadores de la salud no solo deben enfrentar la tragedia de esta horrible enfermedad, sino que hay muchas aristas involucradas en esta situación. Actualmente soy residente de medicina interna en 4 hospitales diferentes en Nueva York y cuando decidí convertirme en médico hace unos años, nunca en un millón de años hubiera pensado que viviríamos esta pesadilla ni a las diferentes situaciones que tenemos que enfrentamos los médicos todos los días. Tenemos el compromiso de despertarnos a diario, sin saber a qué nos enfrentaremos y luchar para ser fuertes y salvar vidas mientras arriesgamos las nuestras y la de nuestros seres queridos que nos esperan

${ }^{1}$ State University of New York - Downstate Medical Center, EE.UU.

PGY 2 Internal Medicine/ HIV track.

Citar como: Tello-majluf D. COVID 19: Sin distinción de raza, sexo o posición socioeconómica; nadie está seguro. Rev. Fac. Med. Hum. Abril 2020; 20(2):334-336. DOI 10.25176/RFMH.v20i2.2929 
en casa. Nuestros hospitales están abrumados y la carga empeora cada día.

Como los casos en Nueva York básicamente se han duplicado todos los días, comenzamos a ver la ola de pacientes que llegaba en cada turno, y de cada ola aproximadamente la cuarta parte necesitan ser intubabados y transferidos a la UCl. Para darles una idea, en un solo día, uno de los equipos médicos de COVID (de los muchos que existen), intubaron a 8 pacientes. Luego pasamos a tener salas de emergencias completas que no estaban equipadas para manejar tantos casos de COVID-19 a la vez. Los cubículos están separados solo por una cortina con un cartel que dice "Iso" (Aislamiento), como si esa cortina fuera suficiente para proteger al paciente junto a ellos o a los muchos médicos, enfermeras y trabajadores del hospital que tienen que trabajar turnos de 12 horas en esa sala de emergencia todos los días (Figura1A).

Luego, comenzamos a ver morir a varias personas antes de que salieran de la sala de emergencias, y los códigos de paro cardíaco llamaban cada hora. No solo la carga del paciente se volvió extremadamente abrumadora, sino que nos enfrentamos a un problema mayor, nos estamos quedando sin equipo de protección personal (EPP). Para empeorar las cosas, todos tenemos una máscara de respirador N95 por turno (a menos que tenga sangre o se ensucie), 1 juego de gafas y una bata (Figura 1B), si llaman a un código, tenemos que ponernos todo nuestro equipo lo más rápido que podamos y correr a la habitación, pero, aun así, el espacio y el número de personas permitidas dentro es muy limitado $y$, a veces, tratándose de enfermedad muy grave de tratamiento médico inútil, no realizamos reanimación cardiopulmonar. Desafortunadamente, debido a que existe la posibilidad de que el paciente pueda progresar rápidamente a una enfermedad grave y/o a la muerte, cada paciente que entra por la puerta debe tener una discusión sobre los objetivos de la atención, independientemente de si tiene 20 años y es necesario abordar también a donde será dirigido.

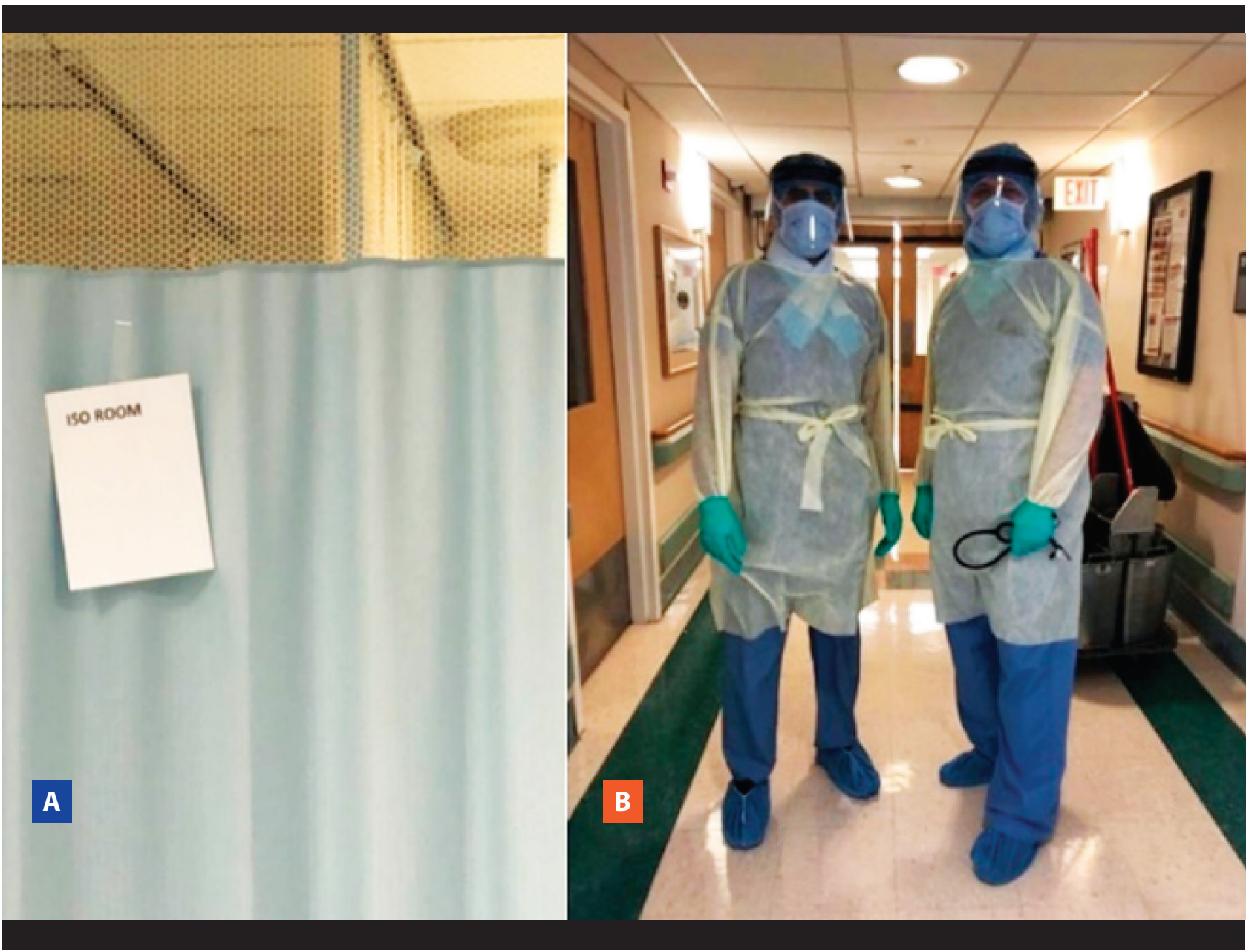

Figura 1. A) Aislamiento en pequeños ambientes de pacientes con COVID-19 separados por una cortina y con un cartel de aviso B) equipo de protección personal. 
Cada vez que vamos a una habitación, aumentan nuestras posibilidades de contraer el virus y cada vez que nos exponemos tenemos que irnos a casa con la preocupación constante de posiblemente infectar a nuestros seres queridos.

Estamos viendo morir a personas de todas las edades, pero cuando nos enfrentamos con los jóvenes de 20 y 30 años que mueren de un paro cardíaco, no puedo evitar verme en ellos, a mí o a mi prometido, que también es residente de medicina interna. No hay visitas autorizadas para estos pacientes infectados con COVID-19, por lo tanto, lamentablemente, estas personas mueren solas.

Cuando suena la alarma y me despierto por las mañanas (cuando he podido dormir), me tomo un segundo para orar, para agradecer a Dios en primer lugar que estoy viva, sana y que puedo ayudar a estas personas. Mientras me pongo el uniforme y conduzco hasta el hospital, digo una segunda oración para darme fuerzas para así poder enfrentar el horror al que tendré que enfrentarme ese día. Y, por último, durante mi jornada en el hospital, oro por mis pacientes y mis colegas al ver la tristeza y desesperación en sus rostros de no podemos salvar a todos. Porque cada día, es peor que el día anterior

A medida que esto empeora y nos preparamos para el vórtice que se avecina, nos enfrentamos a pensar en un futuro que ya está aquí, en donde no tendremos suficientes suministros para continuar atendiendo y en cualquier momento llegaremos al punto que no tendremos suficientes ventiladores eligiendo básicamente, quién vive y quién no. Es en este momento crítico donde se dice que cualquier persona mayor de 70 años y las personas más jóvenes con demasiadas comorbilidades no tendrá un ventilador disponible.
Esta es la parte más triste de todo. ¿Quiénes somos nosotros para decidir quién vive y quién no? Esto no fue parte de nuestro currículo en la escuela de medicina y juramos no hacer daño. Aun así, lo más frustrante de todo es que quieres salvarles la vida, pero no puedes, porque no tienes los recursos ... Esta es la triste realidad que estamos a punto de enfrentar.

Un día, cuando salgamos de esta crisis, miraremos hacia atrás y lo apreciaremos. Este será un recordatorio constante de no dar nada por sentado $y$, nos haremos más fuertes y mejores médicos de lo que nunca imaginamos que podríamos ser, no solo probándonos a nosotros mismos que sobreviviríamos tanto física como emocionalmente a esta barbarie, sino que también nunca olvidaremos a aquellos que cuidamos, que sobrevivieron y que salvamos, o aquellos que desafortunadamente perdimos debido a esta horrible enfermedad. Estoy realmente honrada de ser médico durante esta crisis y definitivamente, será una parte imborrable de mi vida que compartiré con las generaciones venideras.

Contribuciones de autoría: La autora participó en la generación, recolección de información, redacción y versión final del artículo original.

Financiamiento: Autofinanciado.

Conflicto de interés: La autora declara no tener conflicto de interés en la publicación de este artículo.

Recibido: 25 de marzo 2020

Aprobado: 29 de marzo 2020

\section{Correspondencia: Daniela Tello $\mathrm{M}$.}

Dirección: 12 ford st. apt. 5E Brooklyn, NY 11213-EE.UU.

Teléfono: +1 718-270-1000

Correo:Daniela.Tello@downstate.edu 